\title{
ЭКОЛОГО-ЭКОНОМИЧЕСКОЕ ОБОСНОВАНИЕ ПРОМЫШЛЕННОГО КОМПОСТИРОВАНИЯ ОРГАНИЧЕСКИХ ОТХОДОВ
}

\begin{abstract}
ECOLOGICAL-ECONOMIC JUSTIFICATION
OF INDUSTRIAL COMPOSTING
OF ORGANIC WASTE
K. Kuznetsova

N. Molodkina

O. Sergienko

Summary. The relevance of the work is due to the lack of a developed infrastructure in Russia for recycling organic waste by composting, including biodegradable packaging materials that can quickly and safely decompose under the influence of microorganisms under controlled conditions to obtain high-quality organic fertilizer. The conditions under which the large-scale use of compostable polymeric materials is environmentally expedient have been determined. The expediency of creating an infrastructure for industrial composting of organic waste, including biodegradable packaging, has been substantiated; 0 the basis of the performed ecological and economic analysis, it is shown that the most effective option for processing organic waste is the use of closed composting technology in an aerobic bioreactor.
\end{abstract}

Keywords: industrial composting, compost, biodegradation, biodegradable packaging, circular economy.

овременный мир трудно представить без пластиков. Те свойства, за которые пластик получил широкую популярность (прочность, гидрофобность, большой срок годности), стали его основными недостатками.

Начиная с 1998 года, объем образования твердых бытовых отходов (ТБО) вырос почти вдвое. Каждый год количество ТБО, образующихся в результате деятельности человека, растет на 4\% в год. Главной причиной этого явления является увеличение использования полимерных упаковочных материалов [1].

В связи с возникающими экологическими проблемами, связанными с утилизацией полимерных упаковочных материалов, усилия ученых направлены на поиск
Кузнецова Ксения Геннадьевна Национальный исследовательский университет ИТМО, г. Санкт-Петербург kseniasova@gmail.com

Молодкина Нелли Ринатовна

К.т.н., дочент, Национальный исследовательский университет ИТМО, г. Санкт-Петербург

Сергиенко Ольга Ивановна

К.т.н., дочент, Национальный исследовательский университет ИТМО, г. Санкт-Петербург

Аннотация. Актуальность работы обусловлена отсутствием в России развитой инфраструктуры для переработки отходов органического происхождения методом компостирования, в том числе и биоразлагаемых упаковочных материалов, способных быстро и безопасно разлагаться под воздействием микроорганизмов в контролируемых условиях для получения качественного органического удобрения. Определены условия, при которых масштабное использование компостируемых полимерных материалов экологически целесообразно. Обоснована целесообразность создания инфраструктуры для промышленного компостирования органических отходов, в том числе и биоразлагаемой упаковки; на основе выполненного эколого- экономического анализа показано, что наиболее эффективным вариантом для переработки органических отходов является применение технологии закрытого компостирования в аэробном биореакторе.

Ключевые слова: промышленное компостирование, компост, биоразложение, биоразлагаемая упаковка, экономика замкнутого цикла.

и создание альтернативных материалов и методов их переработки.

Существует другая, не менее значимая проблема современного природопользования, связанная с деятельностью человека - деградация почвенного покрова. С истощением запасов гумуса и биофильных элементов, в почвах происходит нарушение органического и минерального питания почвенной биоты, нарушается общая биологическая активность и плодородие почв; снижается устойчивость почв к эрозии, к химическому и бактериальному загрязнению.

На сегодняшний день, проблема бесконтрольного образования пластиковых отходов в мире, и в том числе в России, не решена. $40 \%$ всех образующихся пластиков 
приходится на упаковочные материалы [2]. Основная масса отходов поступает на объекты размещения полигоны ТБО, где разлагается в течение более 100 лет с образованием значительных объемов наиболее опасного парникового газа - метана. В связи с этим актуальность данной темы исследования не вызывает сомнения.

Многие страны Европейского союза, Япония и США уже начали процесс постепенного замещения упаковочных материалов из традиционных пластиков на биоразлагаемые.

Далеко не все полимерные упаковочные материалы с заявленными свойствами к биоразложению действительно могут безопасно разлагаться под действием микроорганизмов. А те материалы, чьи заявленные свойства соответствуют фактическим, не всегда имеют четкие требования к условиям, в которых могут биодеградировать [3]. Основные требования к полимерным материалам, условия их биологической деградации и методики оценки заявленных свойств регламентированы в международных и национальных стандартах стран Европейского союза, Японии и США. В Российской Федерации также существует эквивалентный стандарт по биоразложению упаковочных материалов [4, 5].

Традиционные пластики производятся из ископаемых невозобновляемых источников сырья. В связи с тем, что такое потребление ресурсов не соответствует концепции устойчивого развития общества и экономике замкнутого цикла, набирает популярность производство упаковочных материалов из возобновляемых ресурсов - крахмала, лигнина, целлюлозы [6].

В настоящее время не существует требований, обязующих производителей раскрывать информацию об использовании возобновляемого сырья при производстве упаковочных полимерных материалов, однако со стороны промышленного сектора и среди потребителей неуклонно растет интерес к созданию и использованию экологически безопасных продуктов [7].

На сегодняшний день, можно выделить 2 категории полимерных упаковочных материалов, с заявленными способностями к биоразложению: оксо-биоразлагаемый пластик и компостируемый.

Оксо-биоразлагаемый пластик - пластик, разложение которого происходит в результате протекания двух стадий: оксодеградация (небиологическая стадия) расщепление макромолекул на более короткие звенья под воздействием ультрафиолета или высоких температур и биодеградация (биологическая стадия) - стадия, на которой происходит биологическое расщепление материала под воздействием микроорганизмов на биомассу, воду и углекислый газ $\left(\mathrm{CO}_{2}\right)[8]$.

Под оксо-биоразлагаемыми материалами обычно подразумевают традиционные пластмассы: полиэтилен (ПЭ), полипропилен (ПП), полистирол (ПС) и полиэтилентерефталат (ПЭТФ), в которые были добавлены специальные вещества - каталитические присадки на основе солей железа, магния, марганца, ускоряющие фрагментацию материала. Из этого следует, что основным отличием оксо-биоразлагаемого полимера от традиционного является наличие специальных добавок, ускоряющих процесс фрагментации материала [9].

Компостирование таких видов пластика для получения удобрения невозможно, во-первых, из-за введенных в него добавок (преимущественно солей металлов), которые могут оказывать токсическое действие на растительность, во-вторых, из-за образования микропластика [9].

Компостируемый пластик - пластик, который подвергается деградации в результате биодеградации во время компостирования с образованием углекислого газа, воды, неорганических соединений и биомассы со скоростью, соответствующей другим известным компостируемым материалам, и не оставляет визуально различимых или токсичных остатков [6].

Компостируемые пластики не требуют раздельного сбора, сортировки, переработки в сопоставлении с традиционными пластиками. Но для достижения максимальной биологической разлагаемости они должны компостироваться вместе с органическими отходами наиболее распространенным аэробным способом компостирования [10].

Компостированию подвергаются в основном те органические отходы, которые были собраны раздельно от остальных отходов в специальные контейнеры для этого типа отходов. Компост используется в сельском хозяйстве, поскольку имеет высокое качество и не содержит вредных веществ [11].

Переход на масштабное использование биоразлагаемой упаковки, соответствующей международным стандартам в области компостирования полимерных материалов, является экологически и экономически целесообразной мерой только при условии создания соответствующей инфраструктуры на территории Российской Федерации.

Конечный продукт компостирования - гигиенически безопасное гумусовое вещество, которое можно использовать для стимулирования восстановления 
Таблица 1. Экономические показатели проектов № 1 и № 2

\begin{tabular}{|c|c|c|}
\hline \multirow{2}{*}{ Экономический показатель } & \multicolumn{2}{|l|}{ Величина } \\
\hline & Проект № 1 & Проект № 2 \\
\hline Общие инвестиции $\left(\left.\right|_{0}\right)$, тыс. рублей & 46936,0 & 73479,4 \\
\hline 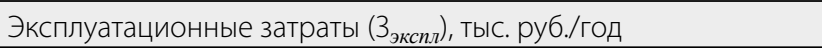 & 24428,5 & 20279,2 \\
\hline Чистая годовая экономия (В), тыс. руб./год & 30970,0 & 43598,8 \\
\hline Простой период окупаемости (РВ), лет & 1,51 & 1,77 \\
\hline Динамический период окупаемости (Т ок $)$, лет & 2,35 & 2,25 \\
\hline Чистая приведенная стоимость (NPV), тыс. руб. & 53586,0 & 73953,0 \\
\hline Индекс доходности (РІ) & 1,14 & 1,01 \\
\hline Внутренняя норма рентабельности (IRR) & $28 \%$ & $27 \%$ \\
\hline Дисконтированные затраты на 1 т готового продукта, тыс. руб. & 1,5 & 1,246 \\
\hline Стоимость 1 т готового компоста, тыс. руб./т & 6 & 7 \\
\hline
\end{tabular}

плодородия почв в качестве органического удобрения. Компостированию могут подвергаться любые отходы органического происхождения: растительные отходы (скошенная трава, ботва, листовой опад); отходы животного происхождения (птичий помет, навоз); пищевые отходы - овощные очистки, кофейный жмых, яичная скорлупа, отходы чайного производства; осадки сточных вод; компостируемые пластики [12].

Компостированию могут подвергаться и органические отходы от промышленных предприятий. Это позволит повысить экологический имидж компаний и решит вопрос с утилизацией отходов на предприятии.

К сожалению, компостирование не является широко распространённым методом утилизации органических отходов ввиду ряда недостатков: продолжительный производственный цикл, мониторинг и поддержание определенных условий, возможность получения нестабильного итогового продукта.

В существующей реальности основным методом утилизации органических отходов является захоронение. С экологической точки зрения размещение органических отходов на полигонах ТБО неприемлемо по нескольким причинам:

- потеря питательных веществ, которые можно использовать повторно;

- органические отходы - это основной источник санитарно-эпидемиологической опасности и неприятных запахов, поэтому перед отправкой отходов на полигон необходимо извлекать из них органическую фракцию, которую необходимо подвергать биологической обработке или компостированию.

В работе был рассчитан годовой объем органической фракции отходов в Санкт-Петербурге, образующихся в организациях общественного питания, образовательных учреждениях, магазинах продовольственных товаров. Исходя из нормативных показателей, ежегодно данные учреждения образуют около 282 тыс. тонн органических отходов, которые являются потенциальным сырьем для производства компоста [13]. Для дальнейшего проведения эколого- экономического обоснования строительства станции для промышленного компостирования органических отходов предложено использовать около 5\% отходов от общей массы - 14,1 тыс. тонн отходов.

Для определения наиболее экологически и экономически целесообразной технологии промышленного компостирования предварительно были изучены информационно- технические справочники по наилучшим доступным технологиям [10].

К расчету и проведению сравнительной характеристики предложены две наиболее распространенные в России и за рубежом технологии: технология среднего уровня - буртовое компостирование на открытых площадках и технология закрытого компостирования органических отходов в биобарабанах.

При компостировании в буртах, сырье - органические отходы укладываются в бурты с шириной 3-6 метров, высотой 1,5-3 метра, длина бурта может быть произвольной. Аэрация осуществляется за счет переворачивания компостного материала с помощью специального ворошителя - переворачивателя. Длительность компостирования составляет 2-4 месяца в зависимости от погодных условий.

Компостирование в барабанном биореакторе является технологией более высокого уровня, длительность процесса сокращается до 3-х суток, за счет непрерывной аэрации, контроля температуры и выхода углекислого газа. Важным этапом является процесс дозревания компоста в кучах для его стабилизации. Срок дозревания компоста составляет 7-10 суток. 


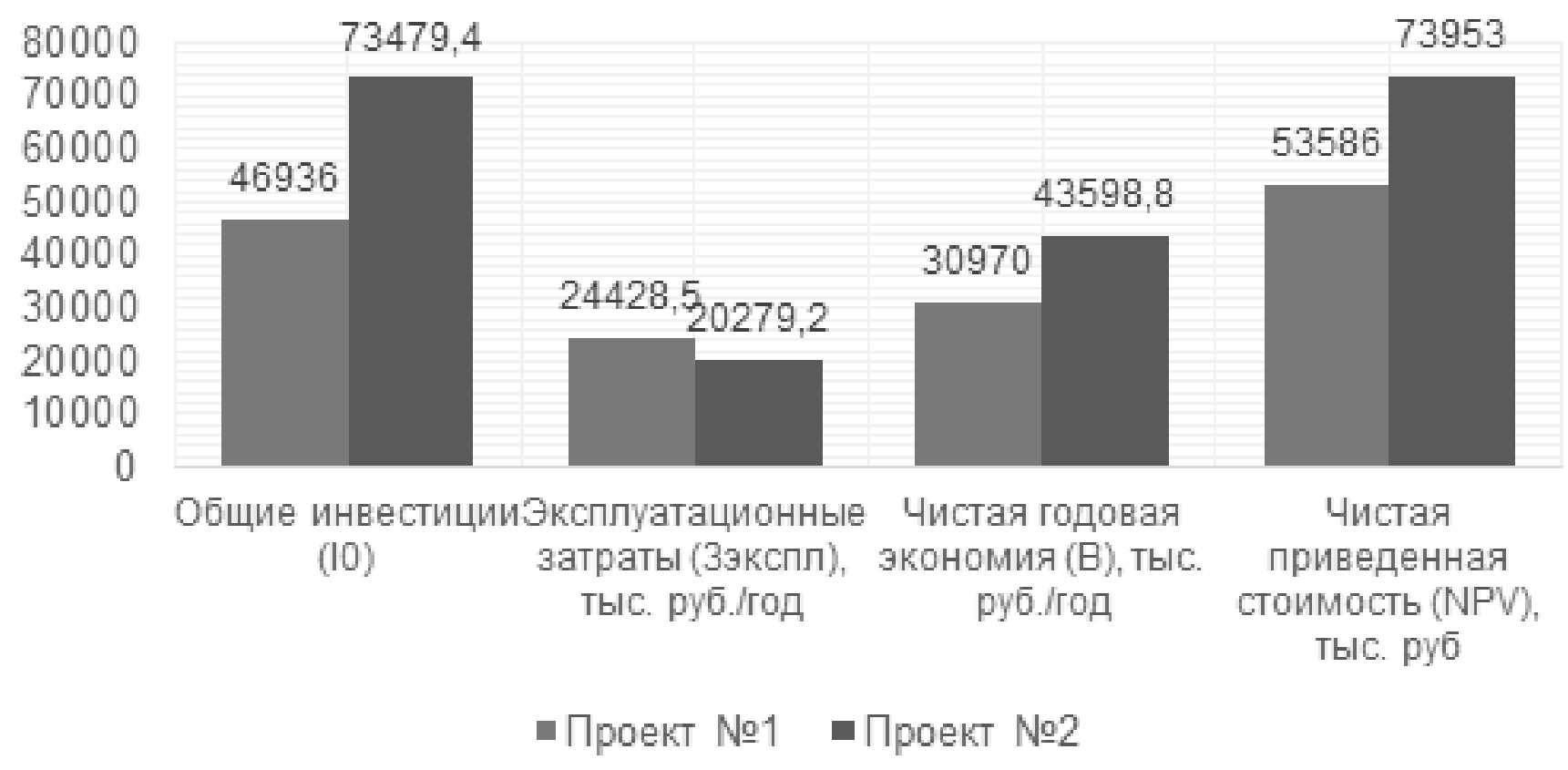

a

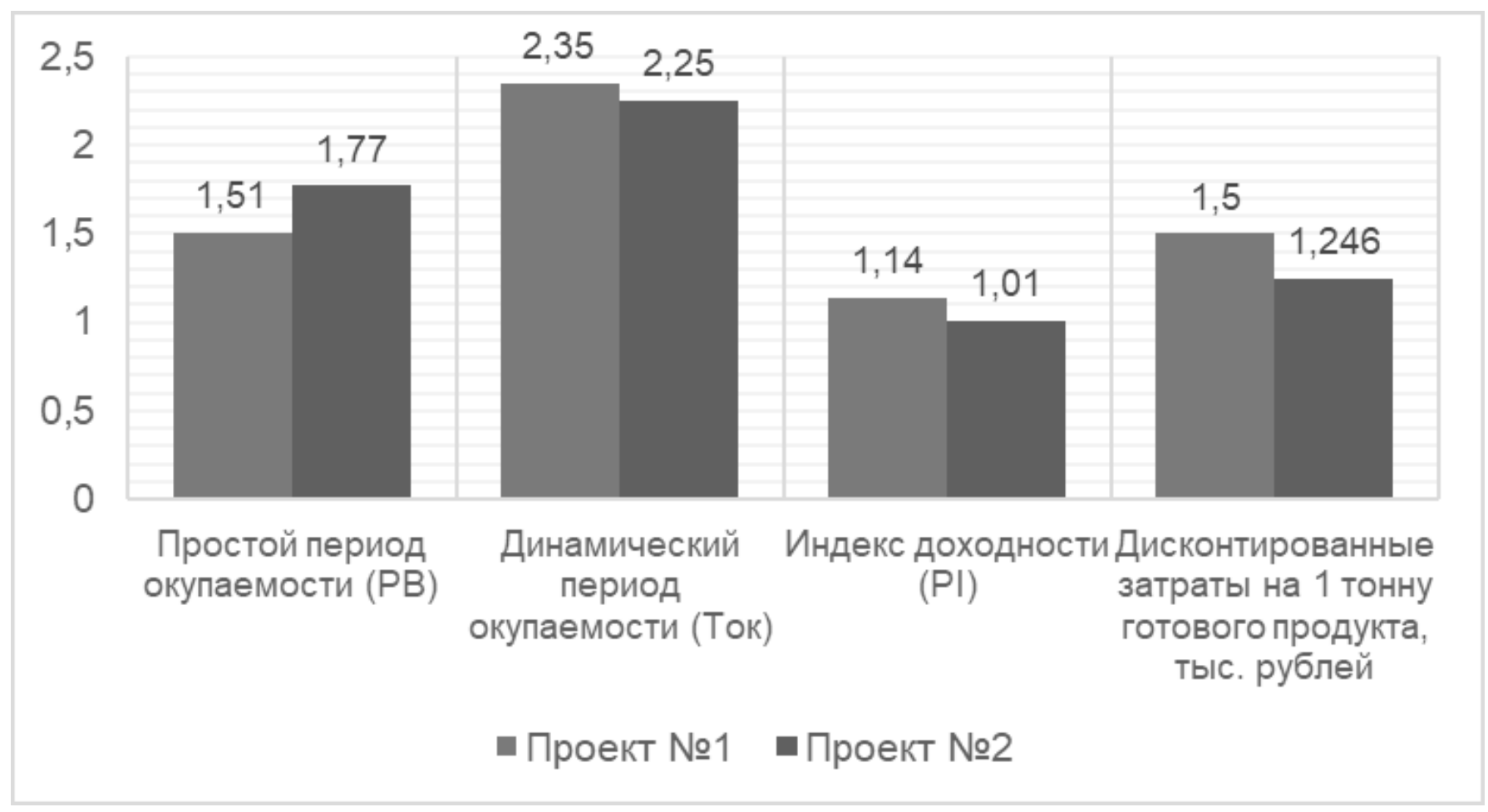

6

Рис. 1. Сравнение экономических показателей проектов № 1 и № 2: капитальные затраты I0, эксплуатационные затраты $3_{\text {экпл' }}$ чистая годовая экономия B, чистая приведенная стоимость NPV (a); простой период окупаемости PB, динамический период окупаемости Ток, индекс доходности PI, дисконтированные затраты на 1 тонну готового компоста, тыс. руб. (б). 
Таблица 2. Расчет эмиссий метана для проектов № 1 и № 2

\begin{tabular}{|l|l|l|}
\hline Показатель & Проект № 1 & Проект № 2 \\
\hline Выход из 1 тонны сырья, кг & 3,28 & 0,26 \\
\hline Выход из всей массы отходов, т/год & 46,228 & 3,664 \\
\hline Удельное образование метана на 1 т готового компоста, кг $\mathrm{CH}_{4} /$ т компоста & 5,5 & 0,41 \\
\hline
\end{tabular}

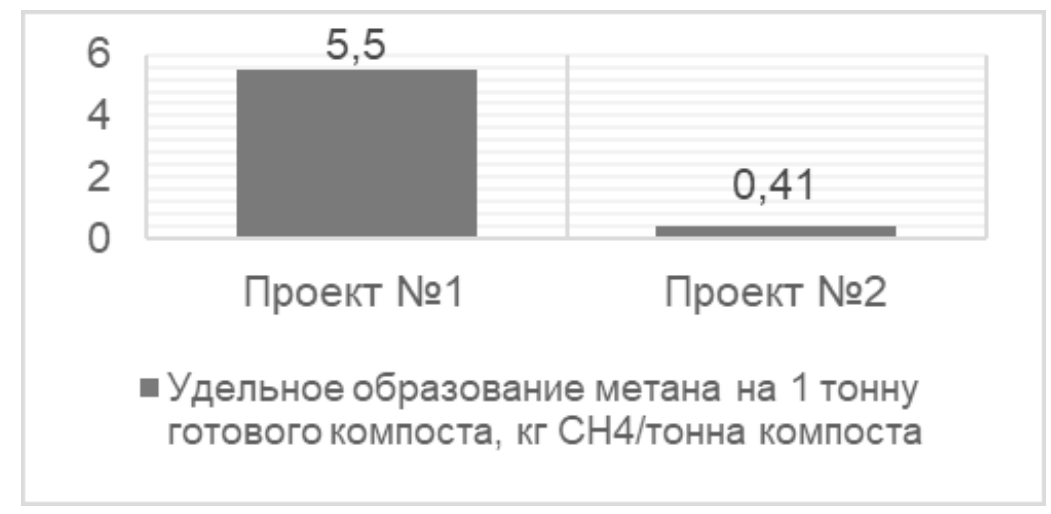

Рис. 2. Показатели удельного образования метана на 1 т готового продукта

Для определения наиболее экономически эффективного проекта проведен расчет капитальных и эксплуатационных затрат на сооружения, оборудование, технические средства, исходя из специфики каждой технологии.

Рассчитанные экономические показатели приведены в таб.1 и отображены на рис. 1.

Расчетный объем готового продукта для обоих проектов составит 28,2 тыс. м³ или 8,45 тыс. т.

Средняя рыночная стоимость готового компоста колеблется в пределах 4-7 тыс. руб. Стоимость компоста при реализации проекта № 1 составит 6 тыс. руб., при реализации проекта № 2-7 тыс. руб. Во-первых, это связано с относительно высоким показателем капитальных

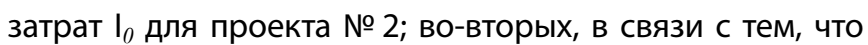
во втором проекте предлагается применение технологии более высокого уровня, следовательно, качество конечного компоста после барабанного реактора будет выше.

При сравнительно высоких капитальных затратах на проект № 2, объем эксплуатационных затрат ниже почти на 4,2 млн. руб. Это связано с высокими затратами на топливо для технических средств при реализации проекта № 1.

Для обоих проектов внутренняя норма рентабельности выше $20 \%$, следовательно, оба проекта являются рентабельными и экономически эффективными.
При определении экологической эффективности проектов был рассмотрен объем образующегося парникового газа метана $\mathrm{CH}_{4}$ для каждого проекта. Метан является наиболее опасным парниковым газом, поэтому, согласно законодательству, устанавливается плата за НВОС (негативное воздействие на окружающую среду) в размере 116,64 руб. за тонну.

Компостирование является аэробным процессом, следовательно, объем образованного метана будет значительно ниже, чем при анаэробном процессе, но при показателе концентрации свободного кислорода $>5 \%$, в компостной системе могут возникать анаэробные зоны.

Согласно литературным данным, при разложении 1 кг органических отходов на полигоне, образуется 77,26 граммов метана $\left(\mathrm{CH}_{4}\right)$, следовательно, 14094 т отходов выделят 1120 тыс. т $\mathrm{CH}_{4}$ [14].

Согласно данным, полученным в работах Sanchez А. и др., при компостировании открытым способом из 1 тонны органических отходов образуется около 3,28 кг метана, а при компостировании в закрытых биореакторах барабанного типа - 0,26 кг. Исходя из литературных данных, рассчитан объем эмиссий метана для каждого проекта (таб.2, рис. 2) от 14094 тонн органических отходов [15].

Плата за годовой объем выбросов метана составит 5380,9 руб. в год для проекта № 1;426,7 руб. для проекта № 2. 
Исходя из расчетов образования метана при компостировании органических отходов на станциях открытого и закрытого типа, можно сделать вывод, что компостирование органических отходов в реакторах закрытого типа, которые используются в проекте № 2, протекает равномернее, следовательно, экологически более эффективно.

\section{Зак^ючение}

В рамках данной работы были рассмотрены экологические и социально значимые вопросы переработки органических отходов. Была обоснована необходимость создания специальной инфраструктуры для переработки органической фракции отходов в безопасное и гигиеничное органическое удобрение - компост.

Выявлено, что компостирование в барабанных биореакторах является наиболее экологически и эконо- мически целесообразным способом переработки органических отходов, данная технология соответствует принциавм НДТ и рекомендуется к внедрению.

Вопрос повсеместного замещения традиционных пластиков компостируемыми недостаточно проработан в нашей стране. Использование компостируемых упаковочных материалов экологически и экономически оправдано только при условии создания инфраструктуры по переработке органических отходов в безопасное удобрение.

Создание инфраструктуры промышленного компостирования орагнической фракции отходов, повысит интерес общества к вопросам экологии, станет фундаментом для внедрения повсеместной переработки отходов и позволит решить важные задачи: получение органического удобрения, снижение антропогенного влияния на окружающую среду.

\section{ЛИТЕРАТУРА}

1. Курбатова А.И., Харламова М. Д. Управление твердыми отходами. Учебное пособие. СПб.: Юрайт, 2019. 312 с.

2. Пластик — новая глобальная экоугроза [Электронный ресурс]. — Режим доступа: http://www.priroda.ru/reviews/detail.php? ID=12475 (дата 06 ращения 5.05.2020).

3. ГОСТ Р 54530-2011 (ЕН 13432:2000) Ресурсосбережение. Упаковка. Требования, критерии и схема утилизации упаковки посредством компостирования и биологического разложения.—-Введен 01.01.2013.- М.: Стандартинформ, 2011. - 14 с.

4. IS0 17088: 2008 Specifications for compostable Plastics.

5. EN13432:2000 Packaging - Requirements for Packaging Recoverable Through Composting and Biodegradation — Test Scheme and Evaluation Criteria for the Final Acceptance of Packaging.

6. ASTM D6400-19 Standard Specification for Labeling of Plastics Designed to be Aerobically Composted in Municipal or Industrial Facilities.

7. Rudnik E. Compostable Polymer Materials. - Elsevier, 2008.— $224 \mathrm{p}$.

8. ГОСТ 33747-2016 «0ксо-биоразлагаемая упаковка. Общие технические условия».—- Введен 01.03.2017.— М.: Стандартинформ, 2011.— 23 с.

9. Thomas, N.L. et al., 2012. Oxo-degradable plastics: degradation, environmental impact and recycling // Proceedings of the Institution of Civil Engineers. Waste and Resource Management. - 2012.-V. 17(165). P. 133-140.

10. ИТС 32-2017 Производство полимеров, в том числе биоразлагаемых. М.: Бюро НДТ, - 2017. - 411 с.

11. Старостина В. Ю. Учебное пособие. Основы компостирования и механико-биологической обработки отходов.—И.: ИРГТУ, 2009.—76 с.

12. ГОСТ Р 55571-2013 «Удобрения органические на основе твердых бытовых отходов. Технические условия».— Введен 01.01.2015.— М.: Стандартинформ, - 2017. - 25 c.

13. Распоряжение № 30-р Комитета по тарифам Санкт-Петербурга от 14.04 .2017 «0б установлении нормативов накопления твердых коммунальных отходов на территории Санкт-Петербурга [Электронный ресурс].—Режим доступа: https://www.gov.spb.ru/gov/otrasl/energ_kom/documents/npa/7118/ (Дата 06ращения: 4.05.2020).

14. Бабаев В.Н., Горох Н. П., Коринько И. В. Энергетический потенциал метанообразования при мезофильном анаэробном разложении органической составляющей отходов // Восточно-Европейский журнал передовых технологий. Технологический центр.— 2011.— № .4(6).— ( 59-65. [Электронный ресурc].—Режим доступа: https://www.elibrary.ru/item.asp?id=19135530 (Дата обращения: 7.05.2020).

15. Sanchez A., Artola A., Fon, X., Gea T., Barrena R., Gabriel D., MondiniC. Greenhouse Gas from Organic Waste Composting: Emissions and Measurement // Environmental Chemistry Letters - 2015. - V. 13(3).-P. 223-228.

○ Кузнецова Ксения Геннадьевна ( kseniasova@gmail.com ), Молодкина Нелли Ринатовна,

$$
\text { Сергиенко Ольга Ивановна. }
$$

Журнал «Современная наука: актуальные проблемы теории и практики» 